\title{
Disability and Vulnerability: Challenging the Capacity/Incapacity Binary
}

\section{Beverley Clough}

Centre for Law and Social Justice, School of Law, University of Leeds

E-mail: b.clough@leeds.ac.uk

This article engages with emerging debates in law and feminist philosophy around the concept of vulnerability. Central to this is the call to re-imagine and re-frame vulnerability as universal - as something which is experienced by all individuals, by virtue of their humanity and context as social beings. The implications of this for laws and policies predicated on groups or categories as 'being vulnerable' will be explored in this article, using the concept of mental capacity as an example of how the boundary between capacity and incapacity can be contested through this lens. The article will critically consider the Mental Capacity Act 2005 and associated literature, such as Court of Protection cases, the House of Lords Select Committee's post-legislative scrutiny and Serious Case Reviews, which demonstrate the growing concern about the inadequacy of the binary between capacity and incapacity. This in turn provokes a challenge to accepted wisdom in the context of disability more broadly, inviting us to think in particular about the responses to perceived vulnerability that are currently deemed appropriate. Insights from the legal literature invite further exchanges with social policy theorists as to the concept of vulnerability and its challenges and implications for law and policy.

Key words: Mental Capacity Act 2005, vulnerability, responsive state, disability, social model of disability.

\section{Introduction}

As commentators have noted - and this themed section is testament to - normative theorising of the concept of vulnerability and its implications for policy is increasingly common, and we are embroiled in a 'vulnerability zeitgeist' (Brown, 2014). Given concerns about the way in which vulnerability discourse may be used to create dangerous new categorisations and binaries, and to effect social control and paternalistic intervention in the lives of those classed as vulnerable, it is important that we do not valorise vulnerability as a guide for new modes of legal and policy reform. This is perhaps most salient in contexts such as disability and adult social care, where the concept of vulnerability is eyed with suspicion due to its perceived synonymous relationship with weakness and powerlessness, and its traditional ascription to disabled people to enable controlling interventions.

This article engages critically with the range of literature that has developed more recently, which conceptualises vulnerability as a shared, universal ontological experience for all human beings, by virtue of our nature as interdependent social beings (Turner, 2006; Fineman, 2008, 2014, 2015; Fineman and Grear, 2013). The theorising of vulnerability which has developed through the works of feminist legal scholars and philosophers 
challenges traditional conceptions of vulnerability as an internal characteristic, demonstrating the ways in which seeing vulnerability as a universal embodied condition shifts the focus onto the structural and institutional conditions that expose this vulnerability. Central to this idea of universal vulnerability is a call to reimagine the legal subject. As Fineman stresses, the dominant political and legal subject presents an impoverished view of humanity, presented as being a competent, capable, self-sufficient and self-actualising agent who 'seeks liberty or autonomy as a primary value' (Fineman, 2015: 617).

As will be demonstrated in this article, this liberal subject frame has particular influence in the context of mental capacity law. Much in modern health and social care policy is about 'choice' (see Wilson, 2014), and this is closely aligned to the concept of capacity - indeed, in some respects it is reserved for those with capacity (see, for example, the No Secrets supporting guidance: Department of Health, 2000, para. 6.21). The statutory framework created by the Mental Capacity Act 2005 (MCA) demarcates the boundaries of the concept of mental capacity and the legal responses available if an individual is deemed to lack mental capacity. There is here an overlap with the 'vulnerable adult' concept, as individuals who could fall within the boundaries of the MCA (those with an impairment of, or disturbance in the functioning of, the mind or brain - see s2(1)) may also fall within the definition of the 'vulnerable adult', previously defined as:

A person aged 18 or over who is or who may be in need of community care services by reason of a mental or other disability, age or illness; and who is or who may be unable to protect himself or herself against significant harm or exploitation. (No Secrets, Department of Health, 2000: 2.3)

Now the terminology has been shifted to 'adult at risk' by the Care Act 2014 (s42), as a result of criticisms of the No Secrets definition as being too status focused. Whether this shift in terminology will have any impact on our legal approach to vulnerability remains to be seen, and a wholesale shift is perhaps unlikely, particularly given that the link between the impairment or ill health and vulnerability still persists and is central to the definition.

What is clear through the interaction of the 'vulnerable adult'/'adult at risk' concept with the concept of mental capacity is that binaries, with legal implications, begin to develop between capacity/incapacity and vulnerable/invulnerable. An intimate link is created, threading ideas of impairment, ill health and need for social care to vulnerability and potential incapacity. This then opens up the legal route to see decisions as legally ineffective, whereas those who are deemed to have capacity are seen as autonomous and thus entitled to make their own legally effective decisions and exercise choice.

This article demonstrates that more recent theoretical accounts of vulnerability provide a mechanism not only to challenge the status-based conceptualisations of vulnerability and incapacity, but also to challenge the legal responses and interventions. I suggest that a positive reclaiming of the concept of universal vulnerability can have profound consequences for law and policy here. In an approach which resonates with the social model of disability, focusing on the internal decision-making abilities of individuals is seen to marginalise the multi-variant and multi-dimensional factors which impact on meaningful decision making for all individuals, regardless of impairment. Such an approach demonstrates the need for attentiveness to the structural and institutional factors that interact to reveal particular experiences of vulnerabilities, and for careful responses 
to these. Such responses should have, at their core, a focus on facilitating capabilities and resilience through systemic and institutional shifts.

After considering current critiques of the MCA, stemming from academic commentary, post-legislative scrutiny and Serious Case Reviews, the article will move on to consider the normative utility of vulnerability theory in furthering these criticisms. This article will develop this literature by demonstrating the theoretical threads linking the concept of universal vulnerability with the social model of disability, in order to argue for a more responsive state - and legal framework - with implications reaching beyond mental capacity law.

\section{The Mental Capacity Act 2005}

In the context of adult social care and health care, the Mental Capacity Act 2005 (MCA) draws the parameters of legitimate legal intervention in relation to adults deemed to lack mental capacity. Thus, the distinction between mental capacity and incapacity is crucial. In essence, if an adult is deemed to have mental capacity to make a particular decision, then that decision cannot be interfered with - it is seen as a manifestation of the individual's choice and self-determination, and, as such, worthy of respect as an autonomous decision. Conversely, if an individual is deemed to lack mental capacity in relation to the particular decision, then it is deemed to not be an autonomous decision worthy of such respect, and a substitute decision can be made by another in their 'best interests'.

The Act governs a wide range of decisions, from the minutiae of day-to-day decisions such as what to eat, what to wear and where to go, to medical treatment decisions, residence decisions, decisions as to contact with particular individuals, marriage and capacity to consent to sex. One of the key principles guiding the Act is the presumption of mental capacity (MCA, s1), which means that everyone is assumed to have mental capacity to make a decision, unless it can be proved that they lack capacity. Section 2 outlines the diagnostic element of mental capacity, outlining how 'a person lacks capacity in relation to a matter if at the material time he is unable to make a decision for himself in relation to the matter because of an impairment of, or a disturbance in the functioning of, the mind or brain'. Section 3 of the Act goes on to define what is meant by 'unable to make a decision' and, if a finding of incapacity is made, the Act further lays out that decisions must be made for that individual in their 'best interests' (MCA, s4).

At the core of a capacity assessment is the 'causal nexus' between the impairment of, or disturbance in the functioning of, the mind or brain, and the inability to understand, retain, use or weigh information or communicate the decision. Essentially, if there is no cognitive impairment present, then capacity will not be called into question. Likewise, even if there is an impairment present, the individual will be deemed to have capacity if it cannot be shown that it is that impairment which is causing the inability to understand, use, weigh or communicate information. The result of this assessment of mental capacity is crucial; if an individual is deemed to have capacity, then their decision will be respected and will be deemed to be autonomous. On the other hand, if they are deemed to lack mental capacity, then a decision can be taken for them provided that it is in their best interests. The problematic nature of this stark binary was recognised by the House of Lords Select Committee (2014) in their post-legislative scrutiny of the statute, noting among other things that: 
The presumption of capacity, in particular, is widely misunderstood by those involved in care. It is sometimes used to support non-intervention or poor care, leaving vulnerable adults exposed to risk of harm. In some cases this is because professionals struggle to understand how to apply the principle in practice. In other cases, the evidence suggests the principle has been deliberately misappropriated to avoid taking responsibility for a vulnerable adult. (Para. 3)

This has been echoed in the findings of a number of Serious Case Reviews in the past, including those related to Steven Hoskin and Gemma Hayter, which have been set up to see what lessons can be learnt following the murders of individuals who have been known to adult health or social care services (see, for example, Flynn, 2007; McAteer, 2011). In relation to Steven Hoskin, disengagement with services had been respected as his 'choice', which is an aspect that faced heavy criticism. Whilst the presumption of capacity underpinning the MCA noted above was seen as positive in terms of preventing widespread and unrestrained interventions into people's decisions, it can prove to be problematic in practice (Keywood, 2010: 109). Because Steven was presumed to have mental capacity, this was perceived as a barrier to service engagement, as this would ostensibly go against his expressed wishes. The concept of mental capacity in these cases artificially constructs the individual deemed to have mental capacity as being autonomous. The creation of this stark binary perpetuates the 'othering' of those deemed to lack capacity, and justifies differential legal treatment. Those who do not fit neatly into this constructed binary fall outside of the margins.

Similar issues with the stark binary are demonstrated in the case law in the Court of Protection, which makes decisions on financial and welfare matters for people deemed to lack capacity, as well as making declarations as to capacity and best interests. Herring and Wall outline some of the problematic case law in which this binary plays out, particularly in the context of capacity to consent to sex, consent to contact and consent to residence (Herring and Wall, 2015; Herring, 2016). Such cases pose difficulties for the MCA as they involve complex issues of interpersonal relationships that trouble the decision-specific, functional test for capacity, which tends to be abstract and side-lines the situational context of decision making (also see Clough, 2014).

One such case, PC \& Anor v. City of York Council [2013] EWCA Civ 478 demonstrates this well. The case involved the core issue of whether PC had capacity to decide whether to live with her husband upon his release from imprisonment for serious sexual offences. PC had mild learning disabilities and had married PC whilst he was in prison. It was found that as she had had the capacity to marry she must now be taken to have capacity to decide to perform the terms of the marriage contract. As such, PC was held to have mental capacity to decide on whether to reside with her husband. Lewison LJ summed up the position thus:

adult autonomy is such that people are free to make unwise decisions, provided that they have the capacity to decide ... We must leave PC free to make her own decision, and hope that everything turns out well in the end. (Para. 64, emphasis added)

In IM v. LM \& Others [2014] EWCA Civ 37 questions arose as to LM's capacity in relation to contact with her partner $A B$, and also her capacity to consent to sex with him. This was against a background of 'aggressive' behavior and possible abuse. 
In the Court of Appeal, it was held that LM did have capacity to consent to sex with her partner. Embedded in the judgement and similar cases on consent to sex are allusions to pragmatic concerns and the limitations of the MCA in encapsulating the reality of decision making (para. 77). Decision-making of this nature involves complex, separate decisions which interconnect over indefinite periods of time, the nature of which the MCA may struggle to capture. Autonomy also played a significant part in the reasoning:

the information typically ... regarded by persons of full capacity as relevant to the decision whether to consent to sexual relations is relatively limited. The temptation to expand that field of information in an attempt to simulate more widely informed decision-making is likely to lead to ... both paternalism and a derogation from personal autonomy. (Para. 82)

Whilst seductively simple reasoning, this is not without criticism (see Clough, 2014; Herring, 2016). Derbyshire CC v. AC [2014] EWCOP 38, demonstrates the continuing dissatisfaction with this approach. Here, Cobb J discusses the statement of the medical expert, that AC, 'said that even if she did not want sex she would have to go along with it as she wants to be "lovey dovey"' (para. 33). Cobb J expressed his unease with this and the way that the test for capacity to consent to sex does not include this exercise of choice within its scope (para. 36).

Concerns such as those highlighted here have led to calls for a more responsive legal framework that recognises that a richer, more nuanced understanding of autonomy is necessary if we are advocating for meaningful opportunities for the expression of choice and control over our lives. Hinging this on concepts such as mental capacity works to internalise the perceived vulnerability and link it to the existence of a cognitive impairment, rather than considering the structural and institutional norms that can construct, exacerbate and intensify the experience of vulnerability.

\section{Theorising vulnerability and the 'problem' of disability}

Engaging with vulnerability theory allows us to problematise and engage with this binary between capacity and incapacity, and to trouble some of the foundational legal and policy norms that underpin it. As will be seen, this in turn calls for us to consider the adequacy of the responses enabled under the current legal framework, and importantly to reflect outwards on the implications of this analysis for broader legal and policy structures. This section will give a brief overview of key literature which has developed our theoretical approach to vulnerability, particularly in the context of legal discourse, and outline how this poses particular salient issues in the context of disability. It will emphasise the way in which the disability critique of vulnerability can conversely be harnessed to strengthen our understanding of universal vulnerability in light of a nuanced, social model understanding by focusing on the interaction between the embodied individual and their contextual situation in relation to institutions, structures and cultural norms. The central point here is that far from reinforcing categories of 'vulnerable' groups, the universal understanding of vulnerability as shared ontological experience allows us to begin to dismantle and question the binaries, categories and resultant legal and policy responses currently engendered and perpetuated in law. It helps us to reframe our ontological experience as a shared and often positive interaction between our bodies and our context, including through relations with others and institutions. It also brings 
to the fore otherwise obscured or hidden institutional or systemic elements which can exacerbate the experience of vulnerability.

A number of theorists are challenging traditional approaches to vulnerability, which saw it as a group or status based concept, linked to an inherent condition such as age or disability, and seeking to situate the concept within understandings of all individuals as interdependent, relational and, as such, universally ontologically. At the forefront of this is the work of Martha Fineman who has sought to re-imagine, at a political level, what we mean by vulnerability (Fineman, 2008). Central to Fineman's thesis is the notion of ontological 'universal vulnerability', advancing the idea that all human beings, by the very nature of being social beings, are vulnerable. Whilst an understanding of universal vulnerability may seem to gloss over the individual embodied experience of vulnerability (Mackenzie et al., 2014: 16), theorists emphasise that the particular experience of vulnerability must be understood at the individual level (Fineman, 2010). Fineman refers to this as 'embodied difference', stressing that the 'experience of vulnerability varies according to the quality and quantity of resources we possess or can command' (Fineman, 2010: 21).

The 'responsive state' is a key normative aspect of Fineman's vulnerability thesis, in that an understanding of the various sources of vulnerability forms the basis of a claim that the state must be responsive to these (Fineman, 2010: 13). This signals an important recognition of the role that the state plays in the formation of systemic and institutional sources of vulnerability, and conversely that the state is in a position to ameliorate this and instead foster resilience. Vulnerability again is not seen as an inherent quality that individuals or members of particular groups possess, but instead as an experience constituted by the interaction between an embodied being and their societal context their lived experience. Mackenzie et al. (2014) call for a specific focus on sources of vulnerability - inherent, situational and pathogenic - and the way in which the interplay between these sources impacts on embodied experience (Mackenzie et al., 2014: 7). Notably, their category of 'pathogenic vulnerability' as a subset of situational factors refers to the way in which abusive interpersonal or social relationships, and socio-political oppression or injustice can expose vulnerability (Mackenzie et al., 2014: 9). Moreover, they note that 'pathogenic vulnerabilities may also arise when a response intended to ameliorate vulnerability has the paradoxical effect of exacerbating existing vulnerabilities or generating new ones' (Mackenzie et al., 2014: 9). This is a useful starting point for thinking about the particular experience of vulnerability, in line with Fineman's call for attentiveness to the particular as well as the universal, ubiquitous nature of vulnerability. As will be seen, this is of particular relevance when we consider the framing and application of laws such as the MCA in practice, the legal responses this allows and their actual impact on individual's lived experience.

It is important to consider here the disquiet that is evident in the literature when using a vulnerability frame in the context of disability (Morris, 1991, 1996; Hollomotz, 2009; Roulstone et al., 2011). There is a general concern that an increased focus on vulnerability in the context of welfare can invite policies that reinforce notions of acceptable behaviour (Fawcett, 2009) or of those deemed vulnerable as being passive recipients of care or services (Daniel, 2010). This is reinforced in the context of disability, with commentators such as Hollomotz $(2009,2011)$ expressing concern that framing disabled people as vulnerable can reinforce the powers of professionals and allow people to be subjected to paternalistic or protective actions. Hollomotz empirical work also suggests that protective 
policies in the context of adults with learning difficulties can increase their vulnerability by preventing the individual from developing their own resilience or coping mechanisms (Hollomotz, 2011). Similarly, Dunn et al. argue that in the context of mental capacity, 'substitute decision making' based on the idea of vulnerability as situational (perhaps due to an abusive partner being deemed to be dominating a person's decision making ability) may allow courts to step in with actions that are 'potentially infinite in scope and application' (Dunn et al., 2008: 241) and effect a course of action that is protective. This is further emphasised by Warner who expresses concern that in the context of adult social care, 'vulnerability' is often used synonymously with the concept of risk (Dunn et al., 2008: 32).

These concerns capture the sense that vulnerability as an indicator in social policy can be dangerous, and may lead to interventions which reinforce power positions, which prevent the ability to develop resilience or personal preventive strategies, and which work to normalise 'acceptable' behaviours. However, the contention of this article is that whilst these are certainly valid concerns, this is not a necessary consequence of engaging with vulnerability theory. There is a sense here in which debates are taking place at crosspurposes. The critical vulnerability theory stemming from Fineman and others' work seeks to challenge precisely these trends in law and policy. As will be discussed below, the idea of universal vulnerability is central to challenging the idea in selective welfare systems that certain groups are vulnerable, and that particular (protective or paternalistic) responses are suited to such groups. This is particularly key in the context of disability and cognitive impairment. Moreover, the focus on pathogenic vulnerability as developed by Mackenzie et al. (2014) can be seen as capturing and responding to the concerns of Hollomotz (2009) and others who feel that responses to supposed vulnerability may in fact reinforce it. The focus on structures and institutions that is central to vulnerability theory enabled a nuanced and careful analysis of the professional and interpersonal power relations and sees such issues as the locus of concern, rather than the individual - which has important theoretical links with the social model of disability.

The social model of disability holds that much of the disadvantage experienced by those with disabilities or impairment is socially imposed rather than pertaining to their bodily or mental state. In its early form, the central ideas of the social model were presented in this statement in the UK of the Union of the Physically Impaired Against Segregation (UPIAS):

It is society which disables physically impaired people. Disability is something imposed on top of our impairments by the way we are unnecessarily isolated and excluded from full participation in society. (UPIAS, 1975)

Such a view contrasts to the medical model that has been dominant in mental health and mental capacity law, which sees 'diagnosis and classification functioning as ends' (Shogren, 2013: 133). Disability, viewed from this perspective, is simply an 'unfortunate state of functioning and being' (Vehmas, 2004: 209) with a resultant focus on biological cure or management of the condition or person.

This critical turn in linking the social model understandings of disability to a vulnerability analysis could have profound repercussions in reigniting and strengthening debates and activism here. The social model approach as it was initially conceived denying a causal link between impairment and disability - has been subject to criticism, 
debate and refinement both from within the social model itself and also from external perspectives (Barnes and Mercer, 2006; Shakespeare, 2014). Writers such as Shakespeare and Watson (2002), Crow (1996) and Morris $(1991,1996)$ have emphasised the need to bring the body back into social approaches to disability, and frame a more refined and inclusive approach which considers and builds responses to disability on the basis of a variety of levels such as physical, psychological, societal, political and cultural. There is not scope to fully explore this here, but it is argued that aligning with vulnerability theory, and in particular the idea that as embodied beings we share an ontological vulnerability, allows a more inclusive, embodied, interactive social model to develop (Wishart, 2003; Clough, 2015). This approach allows us to move away from 'struggling' to 'fit' disability into existing discourses of the legal subject and personhood (Erevelles, 1996). It allows us to construct instead a view of humaneness that begins with our shared ontological interdependencies, and include disability at the outset, echoing the need for 'philosophical inclusive design' (Davy, 2015).

\section{Challenging the capacity/incapacity binary}

This section will focus in particular on what such insights illuminate in the context of the MCA, and in light of the criticisms briefly touched upon in the first section. Two concerns underpin the approach here - one with the idea of a decision being deemed capacitous or incapacitious, and the other being with the legal and policy responses which stem from falling on either side of this divide.

There are many reasons why such a narrow, internally focused approach ought to be a matter for concern. One consequence is that it creates a category of the 'other' in drawing a legal dividing line between those who have capacity and those who do not, which justifies a different legal response. As Scully has argued in considering the relationship between vulnerability and disability, disavowal, hostility and scapegoating of disability, 'reinforced by the conceptual segregation of disabled people into a category marked specially vulnerable, significantly increases the risk that they will be seen as radically other to normative citizens: more dependent, more of a burden, less able to argue for their dependencies to be treated just like the dependencies of everyone else, and more easily jettisoned when times are hard' (Leach Scully, 2014: 219).

Such a concern manifests in the context of the MCA where we can see a stark dividing line between those who have a cognitive impairment, who can thus be capable of being deemed to lack capacity, and those without a cognitive impairment, who cannot. In this respect, the Act may be both over- and under-inclusive. It may be over-inclusive in that it wrongly focuses on those with certain cognitive impairments, such as those with learning disabilities or dementia, and stigmatises them through a lens of disability and incapacity. However, the Act may be under-inclusive in that others who are in abusive relationships, or who are subject to oppression and domination, are left outside of the legal purview because their decisions are deemed to be autonomous as they are not tainted by the presence of a cognitive impairment.

The richer understanding of vulnerability as a universal condition of our ontological experience as human beings calls into question this division between those with cognitive impairments and those without. It sees us all as vulnerable to relationships of domination, to structures that discriminate and allow the unequal distribution of resources necessary to enable meaningful choice, and to cultural and political norms which disavow and devalue. 
At the same time, however, it ought to be noted that our ontological shared vulnerability is also a positive thing - that encourages and in many ways necessitates the forming of relationships of care and support. The idea of universal vulnerability challenges the stark binary line drawn in law between those deemed to have capacity and those deemed to lack it. It calls into question the singling-out of cognitive impairment for differential legal treatment and calls for justification of this. It also obscures the potentially pathogenic sources of vulnerability created or exacerbated by this legal and policy starting point.

One of the reasons why the Mental Capacity Act may have been framed in such a narrow way is due to the pervasive understanding of autonomy premised on noninterference, rooted in the liberal tradition. Interference with individual decision making, from this perspective, is seen as paternalistic and antithetical to respect for autonomy. As such, only in very limited circumstances ought decisions to be questioned in order to avoid unwarranted and unethical interferences with individual liberty. Only those deemed to lack mental capacity can then be subject to paternalistic interference with their decisions, as they lack autonomy. Those deemed to have mental capacity are conversely seen as autonomous, and it is seen as paternalistic and beyond the role of the state to interfere with their decisions. Autonomy and paternalism are thus set up in conflict. Whilst this does not fully address the confining of the Act to those with cognitive impairments, it does signal the ethical and legal distaste for paternalistic intervention in citizen's lives. Indeed, this is a concern expressed in much of the literature, particularly around the concept of vulnerability. Mackenzie et al. (2014) point out that in responding to vulnerability we need to be very cognizant of the way... discourses of vulnerability and protection and the labelling of individuals, groups or whole populations as vulnerable can lead to discrimination, stereotyping and unwanted paternalistic interventions' (Mackenzie et al., 2014: 16; also see Series, 2015: 3).

Whilst these are, of course, valid concerns and reflect the way that policies focused on 'vulnerable' populations may have worked in the past, this is not a reason to dismiss vulnerability as a concept and revert to the traditional liberal and arguably impoverished concept of autonomy. A particularly salient point is raised by Hall in relation to the systems and structures underpinning mental capacity law, who suggests that whilst capacity is the main locus of evaluation in this context, it is in fact perceived vulnerability that health or social care professionals are responding to. The capacity/incapacity framework, however, constrains the response here and leaves the concern with vulnerability 'covert - occurring outside of the official margins, unexamined, undefined, and therefore undefended' (Hall, 2012: 85). Hall goes on to suggest that the 'unspeakable centrality of vulnerability in this context has given rise to the apparent conflict or debate between protection and autonomy that has dominated and distorted the discourse around guardianship for decades. The language of "debate" is, of course, a rhetorical mechanism: in this discourse, 'protection' is the rhetorical straw man in opposition to which "autonomy" is, heroically, defined" (Hall, 2012: 85).

Instead, the literature on vulnerability stresses a richer notion of autonomy which steps outside of these theoretical constraints imposed by thinking in terms of autonomy/paternalism, or empowerment/protection. What is often ignored by such criticisms is the way in which the state, through various structures, institutions and norms, does already interfere in our lives. It is often the case that such structures are normalised and thus made invisible. In contrast to the 'autonomy myth' (Fineman, 2004), pedalled through the liberal legal subject, this recognition of the already pervasive 
impact of our social context helps to avoid falling into the trap of seeing any state involvement as necessarily paternalistic. Whilst it may be presented that we are all free and unencumbered, it is inescapable that we are all impacted upon and shaped by social structures, institutions and discourses. What is important, then, is thinking about how these structures are working, and how they are impacting upon particular experiences.

The critical point here is that when the focus is shifted to the interaction of various sources of vulnerability, we can thus hone in on how responses can best be framed to facilitate autonomy in a thicker and more meaningful sense, which may involve access to particular resources, or supports in making decisions. Mackenzie argues that such interventions are in stark contrast to 'objectionably paternalistic interventions [which] express or perpetuate relationships of domination or inequality among members of a community or between state and citizens' (Mackenzie, 2014: 55, also see 47). This invites a much more careful analysis not only of the contextual experience of vulnerability, but of the way in which responses (and included in this is the legal or policy response of doing nothing) may exacerbate this. On the other hand, there is a need to consider the way that 'doing nothing' in terms of direct intervention in an individual's life may, at the same time, still potentially require alterations at a structural and institutional level to address particular sources of vulnerability. Our ideas as to what we mean by 'intervention' and the levels at which this takes place begin to shift when considered from this perspective. Such a starting point may in turn begin to open up ways to disentangle the linked dichotomy often cited in the context of adult social care between empowerment and protection (Fyson and Kitson, 2007).

Reflecting again on the MCA and the legal responses engendered by this, we have seen that if somebody is deemed to lack capacity, then a decision can be made for them by somebody else in their best interests. It is argued that this legal response may create a pathogenic form of vulnerability, in that attempting to ameliorate vulnerability can conversely entrench it. That is to say that rather than necessarily equipping the individual with the means to facilitate their autonomy and meaningful choice, the decision may be taken out of their hands. For example, in A Local Authority v. H [2012] EWHC 49 (COP), $\mathrm{H}$ was a twenty-nine-year old woman with mild learning difficulties. The evidence in the case suggested an 'early and deep degree of sexualisation' (para. 6), and Hedley J noted that whilst $\mathrm{H}$ may have consented to such sexual encounters, these may have been exploitative or unconventional as they involved multiple sexual encounters at a time, much older men, bisexual oral and anal sex and attempted sex with a dog (para. 9). H was deemed to lack capacity for sexual relations because she realised about sexual health but not how to protect herself; she struggled to say no and she did not fully understand the relevant issues. The response of the MCA, in holding her to lack capacity, was to deprive her of her liberty and to control and manage aspects of her life to prevent sexual relationships from occurring. She was subject to ' $1: 1$ supervision at all times whether in or out of the property and not free to leave the property on any other basis'. Viewed through the critical lens discussed here, we see that this does not foster H's decision making or choices, as decisions are taken out of her hands, actively entrenching her vulnerability. Equally, if an individual is deemed to have mental capacity, either because they do not have a mental disorder, or because a low threshold test of capacity is set as in $I M \vee L M$, then sources of vulnerability are ignored or obscured, and the means of addressing these are similarly discounted in the name of respecting autonomy. This does not make vulnerability disappear, as there is no state of invulnerable 
(Butler, 2004), but it does allow the systems and institutions perpetuating disempowerment to endure.

\section{Conclusion}

As noted in the introduction, the concept of mental capacity is facing increasing challenge. In parallel, there is increasing engagement with vulnerability theory, and theoretical threads being explored linking vulnerability theory to the social model of disability. The article has demonstrated that vulnerability theory and recognition of our universal vulnerability provides an important unifying aspect to the social model of disability, and sees the impact of societal structures and institutions as a shared facet of our embodiment, rather than something unique to people with disabilities. As Bickenbach maintains, this is based on a concept of impairment as 'an infinitely various but universal feature of the human condition' (Bickenbach, 1999: 101; also see Carson, 1995). This avoids the 'othering' that can occur when people with disabilities are seen as ontologically 'different' and thus warranting a separate legal framework. Crucially, this is not to say that this shared vulnerability is experienced in the same way. The importance of focusing on the particular experience is a vital aspect of vulnerability theory and recognises, perhaps more clearly than the social model, that it is the particular individual's interaction with society which is significant. This raises further questions for how we can make law and policy responsive to particular individuals and how interventions or shifts in broader structures or institutions would impact on users of services.

As well as recognising and being attentive to this, the state must frame responses in a way which facilitates resilience and individual capabilities. This poses a significant challenge to the binary divide between capacity and incapacity which permeates law and policy domestically at present, and calls into question the justifications for interference or non-interference that stem from this divide. This is significant in the context of disability, and begins to unravel some of the traditional dichotomies that interweave in this context capacity/incapacity, autonomy/paternalism, empowerment/protection. When considered alongside the UN Committee on the Rights of Persons with Disabilities and debates stemming from this as to Art 12 (the right to equal recognition before the law) and universal legal capacity (UNCRPD, 2014), vulnerability theory opens up questions as to whether our law in this context should be 'disability neutral', given the questioning of the 'scientific objectivity' of mental capacity and the recognition of the impact of structures and institutions on all of our lives. Significantly, the point underpinning vulnerability theory is that such recognition should not then justify a 'hands-off' approach, or 'leaving people to it'. The role of the responsive state is key. The idea of what the state ought to do in order to be responsive thus involves an important normative angle, in addition to being used to critique the current mode of the state. This invites further questions as to how the state can fulfil this role, and whether this necessarily involves a 'benevolent' state - and, indeed, whether the state can ever be value-neutral. There is a need, then, to engage in broader discussion as to how we conceptualise the role and boundaries of the state, and how we can reconceptualise this in light of increasing recognition of the constitutive role systems and institutions of the state, including law and legal norms, can have in exposing our ontological vulnerability. This would have a profound impact on many areas of law and policy, and provokes further research and discussion between scholars in law and social policy. 


\section{Acknowledgements}

The author would like to thank Kate Brown and the anonymous referees for their insightful comments on the paper. Thanks also to Kirsty Keywood, Laura Pritchard-Jones and Paul Skowron for feedback on earlier drafts, and to participants at the 'Vulnerability and Social Justice' workshop at the University of Leeds.

\section{References}

Barnes, C. and Mercer, G. (2006) 'Breaking the mould', in C. Barnes and G. Mercer (eds.), Doing Disability Research, Leeds: The Disability Press.

Bickenbach, J. (1999) 'Minority rights or universal participation: the politics of disablement', in M. Jones and L. Basser Mark (eds.), Disability, Divers-Ability and Legal Change, London: Martinus Nijhoff.

Brown, K. (2014) 'Questioning the vulnerability zeitgeist: care and control practices with "vulnerable" young people', Social Policy and Society, 34, 3, 371-87.

Butler, J. (2004) Precarious Life: The Powers and Mourning of Violence, London and New York: Verso.

Carson, D. (1995) 'Disabling progress: the Law Commission's proposals on mentally incapacitated adult's decision-making', Journal of Social Welfare and Family Law, 15, 5, 304-20.

Clough, B. (2014) 'Vulnerability and capacity to consent to sex: asking the right questions?', Child and Family Law Quarterly, 26, 4, 371-97.

Clough, B. (2015) 'Exploring the potential of relational approaches to mental capacity law', https://www.escholar.manchester.ac.uk/uk-ac-man-scw:266067 (accessed 10.02.17).

Crow, L. (1996) 'Including all our lives: renewing the social model of disability', in C. Barnes and G. Mercer, Exploring the Divide: Illness and Disability, Leeds: The Disability Press.

Daniel, B. (2010) 'Concepts of adversity, risk, vulnerability and resilience: a discussion in the context of the "Child protection system"', Social Policy and Society, 9, 2, 231-41.

Davy, L. (2015) 'Philosophical inclusive design: intellectual disability and the limits of individual autonomy in moral and political theory', Hypatia, 30, 1, 132-48.

Department of Health (2000) No Secrets: Guidance on Developing and Implementing Multi-Agency Policies and Procedures to Protect Vulnerable Adults from Abuse, London: The Stationery Office.

Dunn, M., Clare, I. and Holland, A. (2008) 'To empower or protect? Constructing the vulnerable adult in English law and public policy', Legal Studies, 28, 2, 234-53.

Erevelles, N. (1996) 'Disability and the dialectics of difference', Disability and Society, 11, 519-38.

Fawcett, B. (2009) 'Vulnerability: questioning the certainties in social work and health', International Journal of Social Work, 52, 473-84.

Fineman, M. (2004) The Autonomy Myth, New York: New Press.

Fineman, M. (2008) 'The vulnerable subject: anchoring equality in the human condition', Yale Journal of Law and Feminism, 20, 1, Article 2.

Fineman, M. (2010) 'The vulnerable subject and the responsive state', Emory Law Journal, 60, 2, 251-75.

Fineman, M. (2014) 'Vulnerability, resilience, and LGBT youth', Temple Political and Civil Rights Law Review, 23, 2, 307-29.

Fineman, M. (2015) 'Equality and difference: the restrained state', Alabama Law Review, 66, 3, 609-26.

Fineman, M. and Grear, A. (2013) Vulnerability: Reflections on a New Ethical Foundation for Law and Politics, Surrey: Ashgate.

Flynn, M. (2007) 'The murder of Steven Hoskin: a serious case review', Cornwall Adult Protection Committee, December 2007.

Fyson, R. and Kitson, D. (2007) 'Independence or protection: does it have to be a choice? Reflections on the abuse of people with learning disabilities in Cornwall', Critical Social Policy, 27, 3, 426-36.

Hall, M. I. (2012) 'Mental capacity in the (civil) law: capacity, autonomy, and vulnerability', McGill Law Journal, 58, 1, 61-94. 
Herring, J. (2016) Vulnerable Adults and the Law, Oxford: Oxford University Press.

Herring, J. and Wall, J. (2015) 'Autonomy, capacity and vulnerable adults: filling the gaps in the Mental Capacity Act', Legal Studies, 35, 4, 698-719.

Hollomotz, A. (2009) 'Beyond "vulnerability": an ecological model approach to conceptualizing risk of sexual violence against people with learning difficulties', British Journal of Social Work, 39, 99-112.

Hollomotz, A. (2011) Learning Difficulties and Sexual Vulnerability: A Social Approach, London: Jessica Kingsley.

House of Lords Select Committee on the Mental Capacity Act 2005 (2014) Report of Session 2013-14, Mental Capacity Act 2005 Post Legislative Scrutiny, The Stationery Office, London.

Keywood, K. (2010) 'Vulnerable adults, mental capacity and adult social care refusal', Medical Law Review, 18, 103-10.

Leach Scully, J. (2014) 'Disability and vulnerability: on bodies, dependence and power', in C. Mackenzie, W. Rogers and S. Dodds (eds.), Vulnerability: New Essays in Ethics and Feminist Philosophy, Oxford: Oxford University Press.

Mackenzie, C. (2014) 'The importance of relational autonomy and capabilities for an ethics of vulnerability', in C. Mackenzie, W. Rogers, and S. Dodds (eds.), Vulnerability: New Essays in Ethics and Feminist Philosophy, Oxford: Oxford University Press.

Mackenzie, C. Rogers, W. and Dodds, S. (2014) Vulnerability: New Essays in Ethics and Feminist Philosophy, Oxford: Oxford University Press.

McAteer, K. (2011) 'The murder of Gemma Hayter: a serious case review', Warwickshire Safeguarding Adults Partnership, 19 October.

Morris, J. (1991) Pride against Prejudice: Transforming Attitudes to Disability, Ann Arbor, Michigan: The Women's Press.

Morris, J. (1996) Encounters with Strangers: Feminism and Disability, Ann Arbor, Michigan: The Women's Press.

Roulstone, A., Thomas, P. and Balderston, S. (2011) 'Between hate and vulnerability: unpacking the British criminal justice system's construction of disablist hate crime', Disability and Society, 26, 3, 351-64.

Series, L. (2015) 'Relationships, autonomy and legal capacity: mental capacity and support paradigms', International Journal of Law and Psychiatry, 40, 80-91.

Shakespeare, T. (2014) Disability Rights and Wrongs Revisited, 2nd edn, London: Routledge.

Shakespeare, T. and Watson, N. (2002) 'The social model of disability: an outdated ideology?', Research in Social Science and Disability, 2, 9-28.

Shogren, K. (2013) 'Considering context: an integrative concept for promoting outcomes in the intellectual disability field', Intellectual and Developmental Disabilities, 51, 2, 132-37.

Turner, B.S. (2006) Vulnerability and Human Rights, University Park, PA: Pennsylvania State University Press.

UN Committee on the Rights of Persons with Disabilities (UNCRPD) (2014) General Comment (Number 1) on Art 12: Equal Recognition before the Law, http://www.ohchr.org/EN/HRBodies/ CRPD/Pages/GC.aspx (accessed 10.02.17).

UPIAS and The Disability Alliance (1975) 'Discussion of a fundamental principle', http:// disability-studies.leeds.ac.uk/files/library/UPIAS-fundamental-principles.pdf (accessed 10.02.17).

Vehmas, S. (2004) 'Ethical analysis of the concept of disability', Mental Retardation, 42, 3, $209-22$.

Warner, J. (2008) 'Community care, risk and the shifting locus of danger and vulnerability in mental health', in A. Peterson and I. Wilkinson (eds.), Health, Risk and Vulnerability, London: Routledge.

Wilson, D. (2014) The Making of British Bioethics, Manchester: Manchester University Press.

Wishart, G. (2003) 'The sexual abuse of people with learning disabilities: do we need a social model approach to vulnerability', The Journal of Adult Protection, 5, 3, 14-27. 